\title{
An overview of the HIV epidemic among men who have sex with men in the United Kingdom, 1999-2013
}

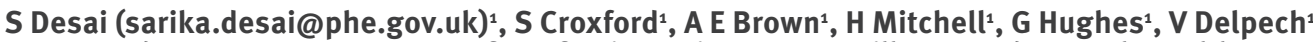

1. HIV and STI Department, Centre for Infectious Disease Surveillance and Control, Health Protection England, London, United Kingdom

Desai S, Croxford S, Brown AE, Mitchell H, Hughes G, Delpech V. An overview of the HIV epidemic among men who have sex with men in the United Kingdom, 1999-2013. Euro Surveill. 2015;20(14):pii=21086. Available online: http://www.eurosurveillance.org/ViewArticle.aspx?Articleld=21086

We describe epidemiological trends in HIV among men who have sex with men (MSM) in the United Kingdom (UK) to inform prevention strategies. National HIV surveillance data were analysed for trends. Multivariable analyses identified predictors of late diagnosis ( 1350 copies $/ \mu \mathrm{L}$ ) and mortality. Between 1999 and 2013, 37,560 MSM ( $\geq 15$ years) were diagnosed with HIV in the UK. New diagnoses rose annually from 1,440 in 1999 to 3,250 in 2013. The majority of MSM were of white ethnicity ( $85 \%$ ) and UK-born (68\%). Median CD4 count increased steadily from 350 cells/ $\mu \mathrm{L}$ to 463 cells/ $\mu \mathrm{L}$. HIV testing in England increased from 10,900 tests in 1999 to 102,600 in 2013. One-year death rates after diagnosis declined among late presenters $(4.7 \%$ to $1.9 \%$ ). Despite declining late diagnosis ( $50 \%$ to $31 \%)$, the number of men diagnosed late annually has remained high since 2004 . Older age ( $\geq 50$ years), and living outside London were predictors of late presentation; older age and late presentation were predictors of one-year mortality. Increases in new diagnoses reflect increased testing and ongoing transmission. Over 900 men present late each year and mortality in this group remains high and preventable. Appropriate prevention and testing strategies require strengthening to reduce HIV transmission and late diagnosis.

\section{Introduction}

In the United Kingdom (UK), as in many other western countries with concentrated HIV epidemics, sex between men is the most important mode of HIV transmission [1]. National HIV/AIDS surveillance was established and coordinated at Public Health England (PHE) (formerly the Health Protection Agency) at the beginning of the 1980s, and has allowed comprehensive understanding and description of the epidemic in the UK [2]. Since the first reports of HIV in the early 1980 , men who have sex with men (MSM) have remained the group most at risk of acquiring HIV in the UK. By the time an HIV antibody test became available in 1984, over 2,000 men had been reported with an AIDS diagnosis. In the late 1980 s and early 1990s, the annual number of new HIV/AIDS cases plateaued but remained high at 1,620 cases, on average, annually [2]. This period was also marked by a rapid increase in deaths until the availability of effective treatment in the mid1990 , which resulted in a marked decline in mortality reports.

Trends in new diagnoses must be interpreted in the context of HIV testing patterns. In the UK, HIV testing services are free and confidential, regardless of residency status, and cross-sectional surveys indicate that the large majority of MSM prefer to undergo HIV testing at sexually transmitted infection (STI) clinics (A Nardone, personal communication, August 2014). Once diagnosed, quality of care is excellent with high retention rates and a near-normal life expectancy among persons diagnosed early [3]. We review 15-year epidemiological trends in HIV diagnoses and testing patterns among MSM to assess the success of prevention efforts and testing strategies. We calculate mortality rates within a year of diagnosis, and in a multivariable model we investigate predictors of late presentation and assess its impact on mortality within one year of diagnosis.

\section{Methods}

\section{Data sources and quality}

We define MSM as men who have ever had sexual contact with another man. The term describes sexual behaviour, regardless of how men perceive their sexual identity. Information on MSM ('men' hereafter) newly diagnosed with HIV between 1999 and 2013 in the UK was obtained from the national HIV and AIDS Reporting System (HARS) held at PHE [4]. HARS has three national surveillance components that collect demographic and clinical information on adults (aged 15 years and older) newly diagnosed with HIV infection from clinicians and/ or laboratories and prospective clinical information (CD4 counts, viral loads, antiretroviral therapy (ART) status) annually collated for all adults seen for HIV care and supplementary $\mathrm{CD}_{4}$ counts from laboratories in England, Wales and Northern Ireland. Scottish data are provided separately by Health Protection Scotland, and subsequently incorporated to create a UK dataset. 
Although national reporting of HIV is not mandatory, returns are linked to commissioning of HIV services and therefore are timely and of high completeness. From triangulation of the data sources, annual lossto-follow-up is less than $5 \%$ [5], ensuring that HARS' coverage is above $95 \%$. Notification delay is minimal $(\ll 2 \%)$ and national figures are not adjusted for delay. AIDS diagnoses and deaths are also reported by clinicians. All-cause mortality for people aged up to 65 years is supplemented from the Office for National Statistics (ONS) death register. Data are linked to HARS using limited patient identifiers (sex, date of birth and Soundex (scrambled surname code [6]). No names are collected on HIV databases kept at PHE and data are kept securely within data protection regulations.

Missing information on probable route of transmission is routinely adjusted for by calculating and applying the proportional distribution of each known exposure group to the overall number of new diagnoses in a given year. Missing exposure information is higher in recent years $(11.5 \%, 690 / 6,000$ in 2013 vs $0.9 \%, 30 / 3,248$ in 1999). We present trends in the overall number of new diagnoses reported annually. Unless specified, we present observed data for all sub-analyses of new diagnoses among men.

Over the past 15 years, completion rates for ethnicity, country of birth and probable country of infection (PCOI) were $99 \%(35,923 / 36,340), 86 \%(31,318)$ and $70 \%(25,352)$, respectively. $\mathrm{CD}_{4}$ counts were available for $89 \%(32,349)$ of new diagnoses with $85 \%(31,000)$ available within three months of diagnosis. To address potential selection biases in completeness of the country of birth field (particularly evident in the earlier years) we calculated a lower estimate of men born in the UK by assuming that all men with a missing country of birth were born abroad, and an upper estimate by assuming all men with missing data were born in the UK. For men born abroad, a published algorithm incorporating information on age, ethnicity, year of arrival in the UK, and $\mathrm{CD}_{4}$ count at diagnosis was used to ascertain and report whether men were infected abroad or in the UK [7]. These adjusted figures are only produced nationally. Elsewhere, observed data on men infected abroad are presented.

Aggregate data on the number of HIV tests performed in STI clinics reported to PHE were used for the years 1999 to 2008 (known as KC60 returns), and after which testing data were reported as part of a disaggregate dataset (known as Genitourinary medicine clinic activity dataset version 2 (GUMCADv2)). KC60 returns included HIV diagnoses and other services provided by all STI clinics in the UK by risk group and for MSM for all ages only. Since 2008, GUMCADv2 has replaced KC60 returns and captures patient-level data, including demographic and clinical history information, on all STI clinic attendees but for England only [4]. As a result we present trends in overall HIV testing data among men attending STI clinics in England for the past 15 years and by age groups for the period 2009-2013.

\section{Definitions}

All persons newly diagnosed with HIV infection have confirmatory laboratory evidence of anti-HIV antibodies. A late HIV diagnosis was defined as having a CD4 count 350 cells $/ \mu \mathrm{L}$ within 91 days of diagnosis. Oneyear mortality was calculated using all-cause mortality within twelve months of a HIV diagnosis among newly diagnosed men in a given year and both measures were expressed as percentages with $95 \%$ confidence intervals $(\mathrm{Cl})$.

\section{Statistical analysis}

Descriptive analyses were conducted on trends in new diagnoses and late diagnoses. Changes over time were investigated using the chi-squared test for trend and non-parametric trend analysis was conducted to investigate changes over time within groups. Nonparametric analysis was conducted to examine trends in median $\mathrm{CD}_{4}$ count at diagnosis.

Univariate analysis was performed to explore associations between demographic attributes and late diagnosis. Variables with marginal associations $(p<0.10)$ were included in multivariable logistic regression analyses, where a stepwise backward approach was used to sequentially remove variables not significant $(p \geq 0.05)$ in order of the $p$ value magnitude. For significant ( $p<0.05$ ) risk factors, adjusted odds ratios (OR) and $95 \% \mathrm{Cl}$ were reported. All statistical analyses were conducted using Stata 13.1 (StataCorp, College Station, TX).

\section{Results}

Fifteen-year trends in the demographic profile of new diagnoses and HIV tests in sexually transmitted infection clinics

Between 1999 and 2013, 37,560 (adjusted) new HIV diagnoses were reported among MSM in the UK, representing $61 \%$ of all MSM diagnosed since the beginning of the epidemic. New diagnoses rose steadily throughout the 15 years, reaching an estimated 3,250 (adjusted) in 2013 compared with 1,440 (adjusted) in 1999 (Figure 1). Among the 36,340 observed new HIV diagnoses, 33,341 (93\%) were diagnosed in England, $1,710(4.7 \%)$ in Scotland, $801(2.2 \%)$ in Wales and $450(1.2 \%)$ in Northern Ireland. The number of HIV tests performed in MSM attending STI clinics across England increased almost 10-fold from 10,900 in 1999 to 102,600 in 2013 (Figure 1), with a steeper rise in testing volume since 2009 .

The median age at diagnosis remained constant at 35 years throughout the period (interquartile range (IQR): $28-42))(p=0.64)$. Annual diagnoses significantly increased in all age groups but increased almost fourfold among younger men (15-24 years, from 131 to 462, p $<0.001$ ) and almost threefold among men aged $\geq 50$ 
Numbers of new HIV diagnoses and HIV tests (England only), men who have sex with men, United Kingdom, 1999-2013

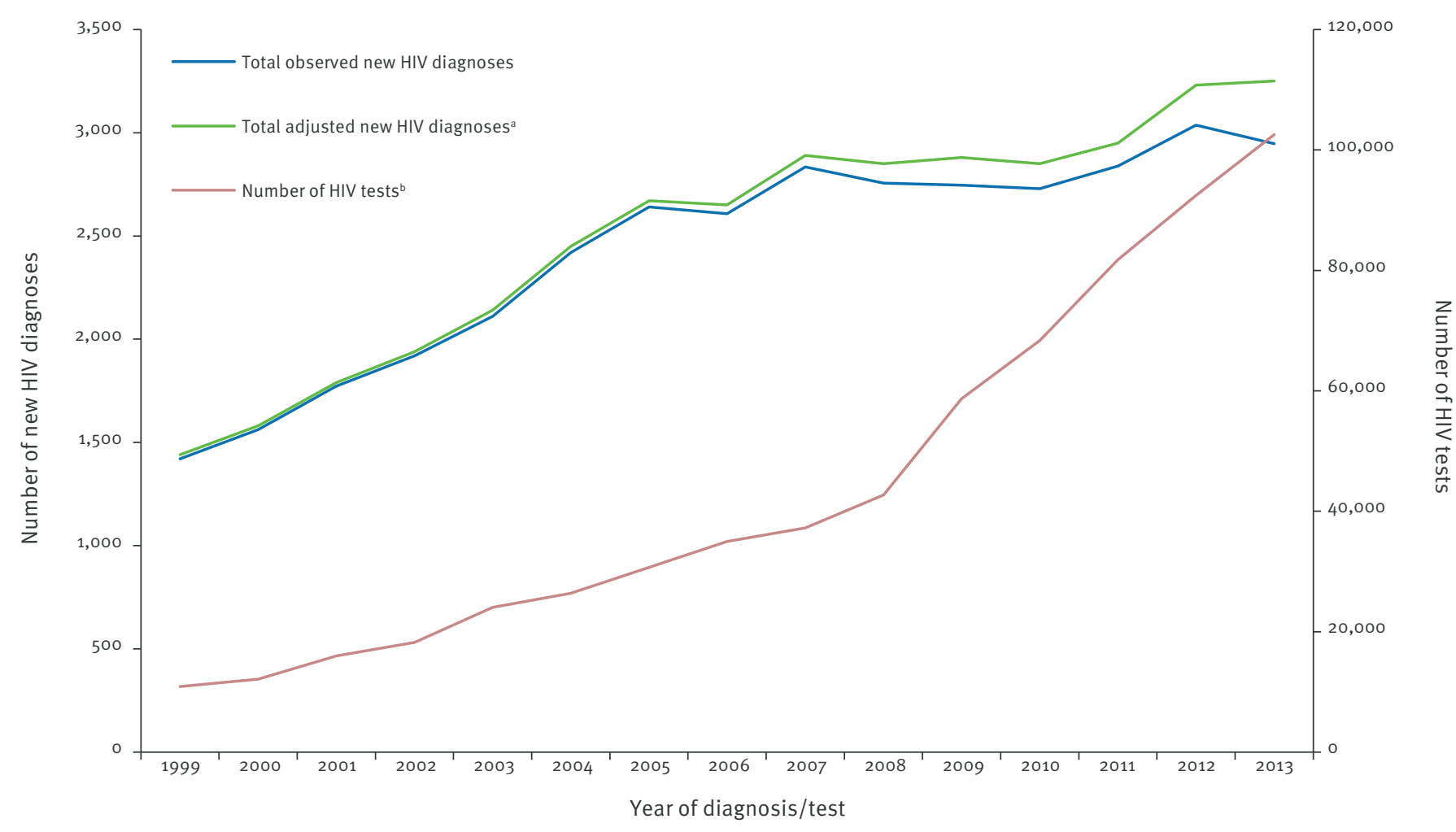

a Data adjusted for missing risk

b Number of HIV tests in England

years (from 115 to 308 , p<0.001). Nevertheless, collectively, three quarters of all diagnoses were reported among men aged $25-34$ years (38\%) and $35-49$ years (40\%).

Overall, the majority of men were white ( $85 \%)$, with some annual change. While absolute numbers were small, among those of other ethnicities, there has been a significant year-on-year increase in new diagnoses among Asian (including Indian sub-continent, Chinese and other Asian) and black African men ( $p<0.001$ ). Diagnoses among black-Caribbean men remained low (annual average: 60, standard deviation (SD): 13.2).

Almost half of all new diagnoses were made in London over the period, although the annual proportion has significantly declined over time from $57 \%(815 / 1,421)$ in 1999 to $50 \%(1,465 / 2,947)$ in 2013 (p<0.001). Overall, diagnoses increased by $34 \%$ in England compared with $53 \%$ in England excluding London.

An estimated $68 \%(21,202 / 31,318)$ of new diagnoses were among men born in the UK (range: $58 \%$ to $72 \%$ when adjusting for missing information). However, diagnoses among men born in other European countries rose from $12 \%$ (90/743) of all diagnoses in 1999 to $20 \%(520 / 2,593)$ in 2013 (Figure 2). Over half of all new diagnoses among European men $(n=4,502)$ were among men born in Spain (15\%), Italy (13\%), Ireland (10\%), France (10\%) and Poland (10\%). Outside Europe, a small but significantly increasing proportion of all diagnosed men was born in Asia $(2.2 \%(n=17 / 743)$ in 1999 to $5.9 \%(n=152 / 2,593)$ in 2013 , p<0.001) and in Latin America (2.8\% (21/743) to 5.3\% $(n=137 / 2,593)$, $\mathrm{p}=0.01$ ) (Figure 2). Overall, two thirds of non-UK-born men were white compared with $94 \%$ of UK-born men.

Over the period, two thirds of diagnoses $(15,803 / 24,082)$ were in UK-born men who probably acquired their infection in the UK; the figure for 2013 was $59 \%(1,173 / 2,005)$. Of the 1,629 of men diagnosed in 2013 who probably acquired their infection in the UK, $72 \%$ were UK-born and $12 \%$ were born in other European countries. In comparison, only $16 \%$ of men who were probably infected outside the UK were born in the UK ( $p<0.001)$.

The median CD4 count at diagnosis steadily increased from 350 cells/mm 3 (IQR: $155-530$ ) to 463 cells/ $\mu L$ (IQR: $307-641)$ over the 15 years ( $p<0.001)$. A statistically significant increase was observed among all age groups except the youngest men and the incline was steepest among men aged $\geq 50$ years (Figure 3 ). Throughout 
Number of new HIV diagnoses by region of birth, men who have sex with men, United Kingdom, 1999-2013

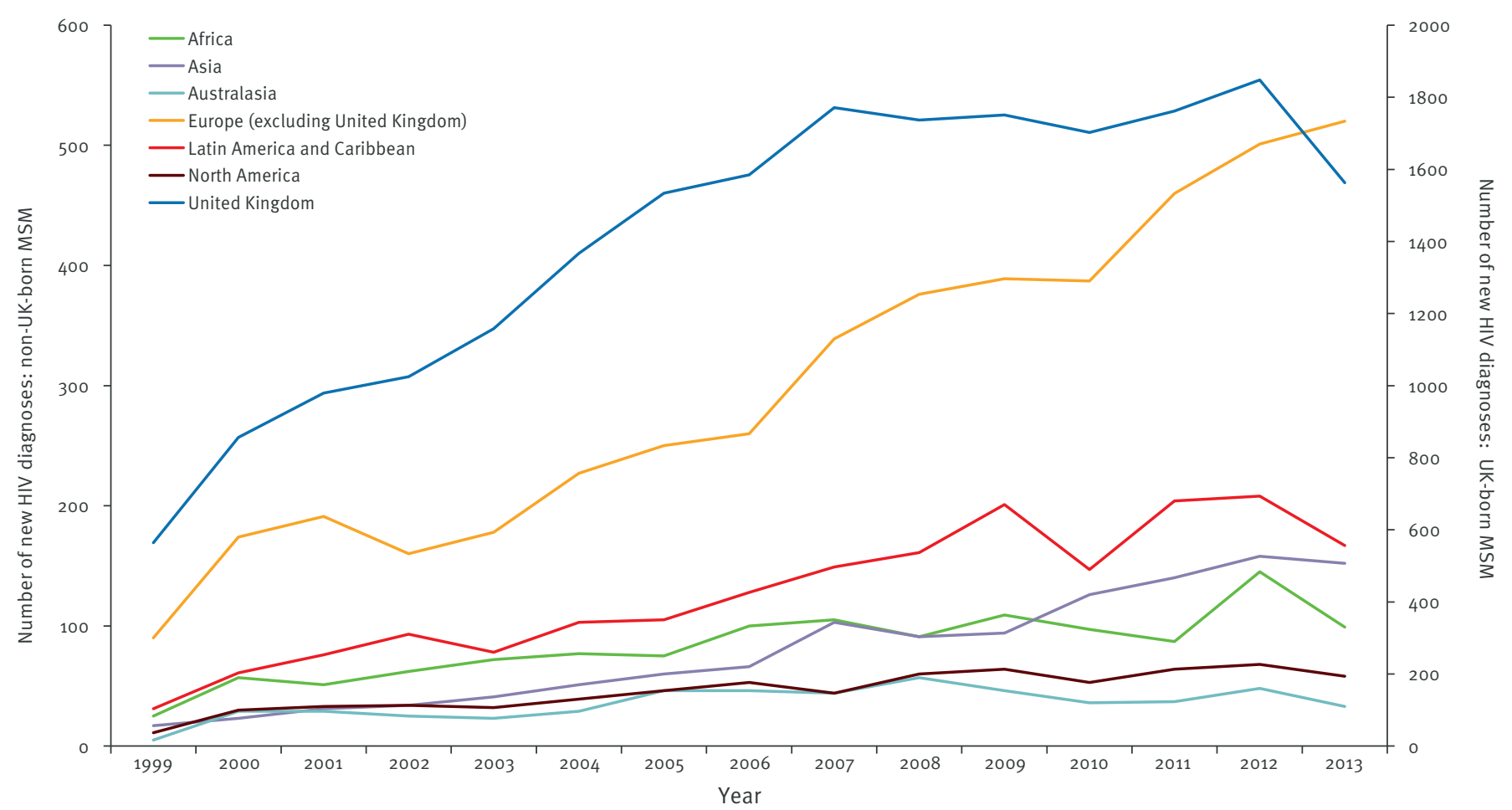

MSM: men who have sex with men; UK: United Kingdom.

the 15 years, median $\mathrm{CD}_{4}$ count at diagnosis remained highest among men aged 15-24 years.

In the last five years, the number of men testing annually has steadily increased in all age groups with the slowest increase among $35-49$ year-olds (46\% vs $69 \%$ among $25-34$ and $\geq 50$ year-olds and $84 \%$ among 15-24 year-olds) (Figure 4). Concurrently, new diagnoses among men of this age group and those aged 50 years and above have remained stable. The greatest increases in testing and new diagnoses were observed among the youngest men.

\section{Late HIV diagnoses}

The proportion of men diagnosed late was $40.8 \%$ (95\% $\mathrm{Cl}: 40.2$ to 41.3$)$ overall with a decline observed over time (from 50\% (95\% Cl: 47 to 53 ) in 1999 to an estimated $31 \%$ (95\% Cl: 29 to 33) in 2013) (p<0.001). The decline was particularly striking by age and ethnicity. Among 25-34 year-olds and those aged 50 years and above, late diagnosis declined from $42 \%(95 \% \mathrm{Cl}: 37$ to 46$)$ to $26 \%$ (95\% Cl: 24 to 29 ) and from $78 \%$ (95\% $\mathrm{Cl}: 69$ to 88 ) to $50 \%$ ( $95 \% \mathrm{Cl}: 44$ to 56$)$, respectively. Among men of black (Caribbean, African and other black (defined as black ethnicities not captured by Caribbean and African ethnicities e.g. black British, black American)) ethnicity, the proportion declined from $69 \%(95 \% \mathrm{Cl}: 55-82)$ in 1999 to $35 \%$ (95\% Cl: 27 to 43 ) in 2013.
The absolute number of annual late HIV diagnoses, however, remained steady (average: 936; SD: 67) since 2004 (Figure 5) including among black men (average: 55; SD: 11). The drop in numbers in 2013 could be due to more missing CD4 count information (2013: 8\% vs 2012: $5.6 \%$ ). There were important differences by demographic variables. The number of late HIV diagnoses increased in men aged 50 years and over from 111 in 2004 to 183 in 2009 and then declined to 140 in 2013. An increase was also evident among men who probably acquired their infection in the UK, from 454 in 2004 to 689 in 2007 (after which the number remained stable). In multivariable analyses, in 2013 older men and those living outside London were more likely to present late (Table 1). Men who acquired their infection outside the UK were no less likely to be diagnosed late.

One-year mortality from HIV diagnosis decreased from $4.6 \%$ (95\% Cl: $3.5-5.8$ ) in 1999 to $0.9 \%$ (95\% Cl: $0.6-$ 1.3) in 2013. The decline was largely due to reduced mortality among men diagnosed late from $4.7 \%$ (95\% $\mathrm{Cl}$ : 3.1-6.9) in 1999 to $1.9 \%$ (95\% Cl: 1.1-3.1) in 2013 ( $p<0.001$ ) (Figure 5). Among men diagnosed with $\mathrm{CD}_{4}$ counts $<200$ cells $/ \mu \mathrm{L}$, mortality declined from $6.6 \%$ (95\% Cl: $4.1-10.0$ ) in 1999 to $3.8 \%$ (95\% Cl: $2.1-6.3$ ) in $2013(p=0.005)$, and from $2.0 \%$ (95\% Cl: $0.5-4.9)$ to $0.2 \%(95 \% \mathrm{Cl}: 0.006-1.3)$ with $\mathrm{CD} 4$ counts between 200 and 349 cells $/ \mu \mathrm{L}$ at diagnosis $(p=0.02)$. Mortality remained highest among men diagnosed late aged 
Median CD4 count at diagnosis by age group, men who have sex with men, United Kingdom, 1999-2013

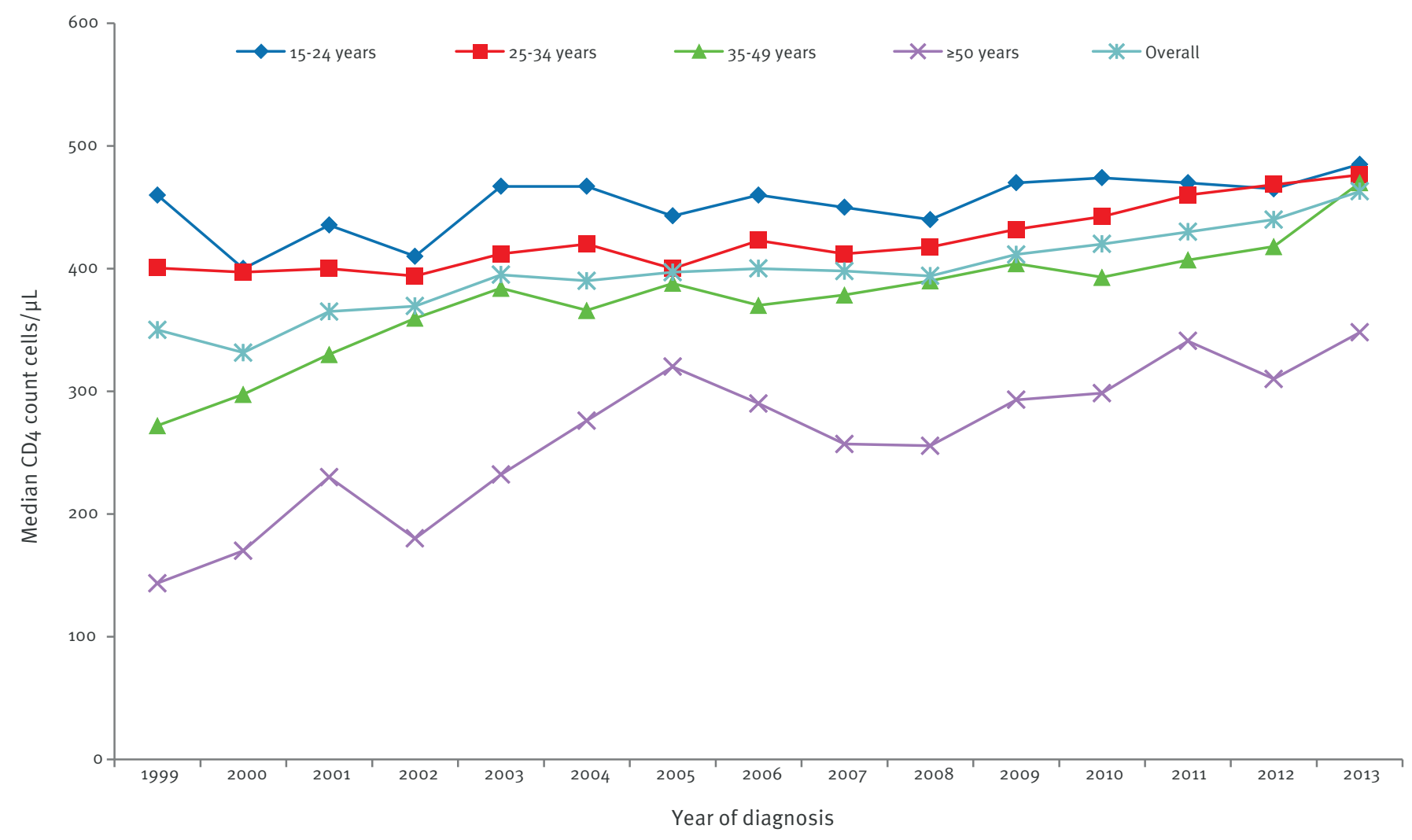

$50+(13 \%, 95 \% \mathrm{Cl}: 5.8-24.2$ in 1999 to $8.6 \%, 95 \% \mathrm{Cl}:$ $4.5-14.4$ in 2013$)$, followed by $35-49$ year olds $(3.9 \%$, $95 \% \mathrm{Cl}: 1.8-7.3$ to $1.0 \%$, $95 \% \mathrm{Cl}: 0.2-2.9)$. In 2013 , in multivariable analyses, older age and a late diagnosis were predictors of dying within a year of being diagnosed (Table 2).

\section{Discussion}

Despite targeted interventions aimed at reducing HIV infections in the UK since the early 1980 s, the past 15 years of the epidemic have seen year-on-year rises in new diagnoses among MSM, with a record 3,250 new diagnoses in 2013. On a positive note, alongside this rise, the volume of HIV tests performed in STI clinics also increased to over 100,000 tests in 2013 and the proportion diagnosed late declined to an estimated $31 \%$. Of concern is the continued high numbers of late presenters and high mortality rate in the year following a HIV diagnosis in this group.

We observed the greatest increases in new diagnoses among younger men. This rise is probably due to sustained HIV transmission as well as increased HIV testing. New diagnoses among younger men are often used as a proxy of incidence, as the time interval between diagnosis and infection is shorter than for older ages. This is also supported by the high median CD4 count at diagnosis in this group, which is indicative of recent infection. During the same period, the number of HIV tests performed increased almost 10 -fold and this is reflected in the decline in time-to-diagnosis interval from 4 years in 2001 to 3.2 years in 2010 [8]. From the age-specific HIV testing data, testing among younger men has also steadily increased. Despite this increase in HIV testing, the number of HIV tests performed in 2011 only equated to an estimated HIV test coverage of $<10 \%$ of the male population in England [9]. Safer sex campaigns with HIV testing and other prevention strategies must be promoted to make an impact on the increasing trends in new diagnoses.

Although surveillance systems differ between countries, new diagnosis trends among men in the UK are broadly comparable to those observed in other European countries [10-12]. This has resulted in an overall increase in new HIV diagnoses among men reported by the European Centre for Disease Prevention and Control (ECDC): with a $36 \%$ increase in new diagnoses observed between 2003 and 2008 in Europe [13]. While an increase among younger men has been reported in other countries, the pattern in new diagnoses among older men is varied [13]. Without concurrent HIV testing data, it is difficult to interpret the rise in new diagnoses reported in other countries. In Norway, the rise has been attributed to increased transmission rather than HIV testing [10]. A proportional decline in late diagnosis among men has been reported across Europe in recent years [13-15]; in central Europe from 


\section{FIGURE 4}

Number of men who have sex with men tested in sexually transmitted infection clinics, England, and number of new HIV diagnoses, United Kingdom, by age group, 2009-2013

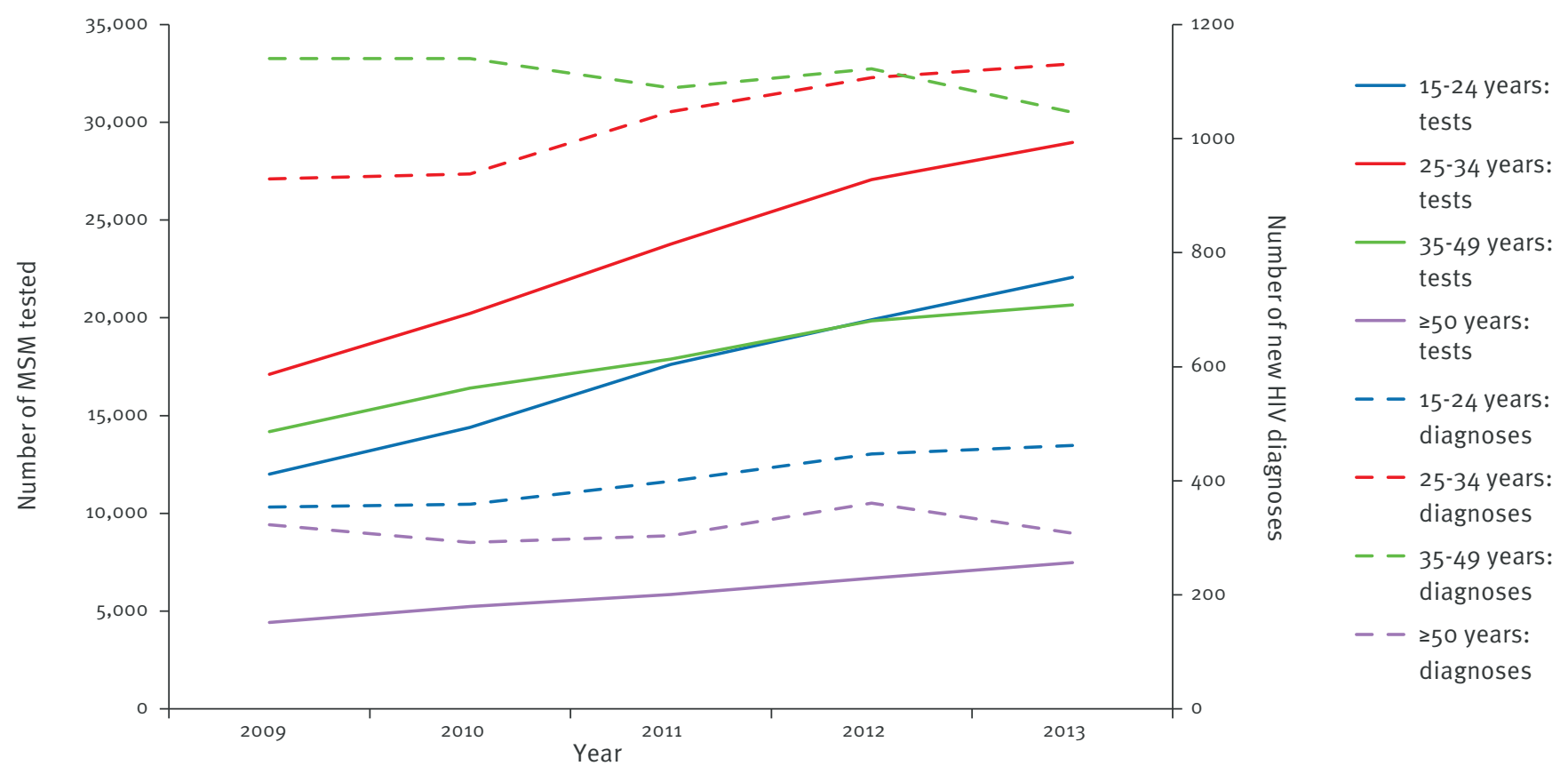

MSM: men who have sex with men.

\section{FIGURE 5}

Late HIV diagnosis and one-year mortality, United Kingdom, 1999-2013

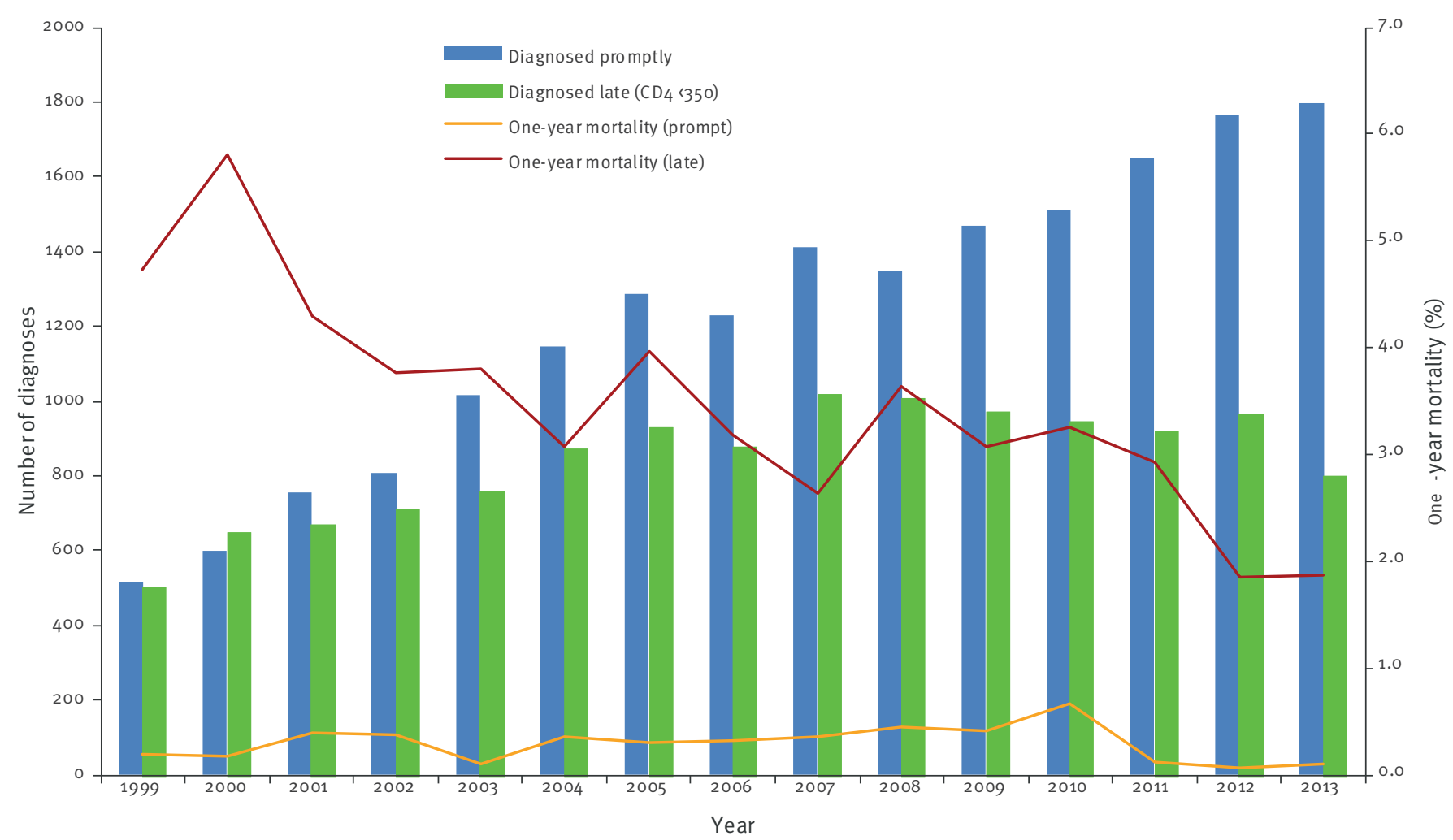


TABLE 1

Multivariable analyses for late HIV diagnosis among men who have sex with men, United Kingdom, 2013 (n=2,602)

\begin{tabular}{|c|c|c|c|c|c|c|}
\hline \multirow{2}{*}{\multicolumn{2}{|c|}{ Variable }} & \multirow{4}{*}{$\begin{array}{c}N^{a}(\%)(n=2,602) \\
1,231(47) \\
1,371(53)\end{array}$} & \multirow{4}{*}{$\begin{array}{c}\begin{array}{c}\text { Number } \\
\text { diagnosed late } \\
(\%)^{\mathrm{b}}(\mathrm{n}=802)\end{array} \\
457(37) \\
345(25)\end{array}$} & \multicolumn{3}{|c|}{ Late HIV diagnosis } \\
\hline & & & & \multirow{2}{*}{$\begin{array}{c}\begin{array}{c}\text { Unadjusted OR } \\
(95 \% \mathrm{Cl})\end{array} \\
1\end{array}$} & \multirow{2}{*}{\begin{tabular}{|c|}
$\begin{array}{c}\text { Adjusted OR (95\% } \\
\mathrm{CI})\end{array}$ \\
1 \\
\end{tabular}} & \multirow{3}{*}{$\begin{array}{l}\text { p value } \\
\text { ८0.001 }\end{array}$} \\
\hline \multirow{2}{*}{ Residence } & Elsewhere, UK & & & & & \\
\hline & London & & & $0.6(0.5-0.7)$ & $0.6(0.5-0.7)$ & \\
\hline \multirow{4}{*}{ Age group } & $15-24$ years & $407(16)$ & $98(24)$ & 1 & 1 & \multirow{4}{*}{$<0.001$} \\
\hline & $25-34$ years & $1,000(38)$ & $263(26)$ & $(0.9-1.5)$ & $1.2(0.9-1.6)$ & \\
\hline & $35-49$ years & $916(35)$ & $301(33)$ & $1.6(1.2-2.0)$ & $1.7(1.3-2.2)$ & \\
\hline & $\geq 50$ years & $279(11)$ & $140(50)$ & $3.2(2.3-4.5)$ & $3.2(2.3-4.4))$ & \\
\hline \multirow{6}{*}{ Ethnicity ${ }^{c}$} & White & $2,035(81)$ & $631(31)$ & 1 & n.a. & \multirow{6}{*}{ n.a. } \\
\hline & Black African & $61(2.4)$ & $22(36)$ & $1.2(0.7-2.1)$ & n.a. & \\
\hline & Black Caribbean & $64(2.6)$ & $21(33)$ & $1.1(0.6-1.8)$ & n.a. & \\
\hline & Black other & $32(1.3)$ & $12(38)$ & $1.3(0.6-2.7)$ & n.a. & \\
\hline & Asian & $144(5.7)$ & $40(28)$ & $0.8(0.6-1.2)$ & n.a. & \\
\hline & Other & $171(6.8)$ & $50(29)$ & $0.9(0.6-1.3)$ & n.a. & \\
\hline \multirow{2}{*}{ UK-born } & No & $924(40)$ & $245(27)$ & 1 & n.s. & \multirow{2}{*}{0.102} \\
\hline & Yes & $1,372(60)$ & $481(35)$ & $1.5(1.3-1.8)$ & n.s. & \\
\hline \multirow{2}{*}{ UK-acquired infection } & No & $376(18)$ & $105(28)$ & 1 & n.a. & \multirow{2}{*}{ n.a. } \\
\hline & Yes & $1,689(82)$ & $533(32)$ & $1.2(0.9-1.5)$ & n.a. & \\
\hline
\end{tabular}

$\mathrm{Cl}$ : confidence interval; n.a.: not applicable (not included in multivariable analyses); n.s.: not significant; OR: odds ratio; UK: United Kingdom.

a Only includes men with $\mathrm{CD}_{4}$ count information.

b Late diagnosis defined as a CD4 count $<350$ cells/ $\mu \mathrm{L}$ within 91 days of HIV diagnosis.

Ethnicities as reported by clinicians. 'Black other' includes black ethnicities not captured by Caribbean and African ethnicities e.g. black British, black American. 'Asian' includes Indian sub-continent, Chinese and other Asian ethnicities and 'other' includes mixed ethnicity.

$52 \%$ in 2000 to $40 \%$ in 2008 and in northern Europe from $48 \%$ to $39 \%[14]$.

Disappointingly, the annual number of men diagnosed late has remained high and stable throughout the decade and in 2013, one in three men was still diagnosed late, at the threshold at which treatment is recommended. As total numbers of new diagnoses have increased, stable numbers of late diagnoses suggest those additional annual diagnoses are probably being diagnosed promptly through repeat testing and/or recent acquisition. In multivariable analysis, older men were more likely to present late and be at increased risk of death within a year of diagnosis. Others have also found increasing age to be a predictor for late diagnosis $[15,16]$. This finding is likely to reflect both delay in diagnosis and steeper CD4 declines following HIV infection in older men [17]. Poorer health outcomes among older adults diagnosed with HIV infection has been previously documented in this population [18]. Together these findings underscore the importance of reaching men who are not regularly testing for HIV and ensuring a prompt diagnosis and access to HIV care and treatment for all men regardless of age.

Reductions in late diagnoses can be achieved through a higher HIV testing coverage. Since 2008, national HIV testing guidelines recommended expanding and normalising HIV testing beyond STI clinics into medical services in areas where diagnosed HIV prevalence is above the threshold of two per thousand among 15-59 year olds [19], and have advocated the development of local strategies to offer HIV testing to men [20]. In addition, late diagnosis of HIV infection has been selected as a key indicator of Public Health Outcome Framework in England since 2010 [21]. Despite these recommendations, there is little evidence to date of local initiatives to expand HIV testing beyond STI clinics [22] and an estimated 8,000-9,000 men remain undiagnosed annually across the UK [8]. The numbers undiagnosed has remained stable throughout the decade and modelling suggests that the large majority of transmissions come from men unaware of their infection [23].

The decline in one-year mortality is an important achievement as it implies that linkage and retention in HIV care have improved, especially among men diagnosed late. The decline also reflects changes to national recommendations on ART initiation. In 2008, the recommendation to initiate treatment was amended from CD4 cell counts $<200$ to $<350 / \mu \mathrm{L}$ [24]. Nevertheless a mortality of $2 \%$ among those diagnosed late is alarmingly high when compared with $0.1 \%$ among men diagnosed promptly. These findings highlight the importance of prompt diagnosis and ART initiation. 
TABLE 2

Multivariable analyses for one-year mortality among men who have sex with men, United Kingdom, 2013 (n=2,195)

\begin{tabular}{|c|c|c|c|c|c|c|}
\hline \multirow{2}{*}{\multicolumn{2}{|c|}{ Variable }} & \multirow{3}{*}{$\begin{array}{c}\begin{array}{c}\text { Number dying } \\
\text { within a year of } \\
\text { diagnosis }(\mathrm{n}=27)\end{array} \\
19\end{array}$} & \multirow{3}{*}{$\begin{array}{c}\begin{array}{c}\text { One-year } \\
\text { mortality }(\%)\end{array} \\
1.2 \\
\end{array}$} & \multicolumn{3}{|c|}{ Late HIV diagnosis } \\
\hline & & & & \multirow{2}{*}{$\begin{array}{c}\begin{array}{c}\text { Unadjusted OR } \\
(95 \% \mathrm{CI})\end{array} \\
1 \\
\end{array}$} & \multirow{2}{*}{$\begin{array}{c}\text { Adjusted OR (95\% } \\
\mathrm{CI})\end{array}$} & \multirow{3}{*}{$\begin{array}{c}\mathrm{p} \text { value } \\
0.652\end{array}$} \\
\hline \multirow{2}{*}{ Residence } & Elsewhere, UK & & & & & \\
\hline & \begin{tabular}{|l|} 
London \\
\end{tabular} & 8 & 0.6 & $0.4(0.2-1.0)$ & \begin{tabular}{|c|} 
n.s. \\
\end{tabular} & \\
\hline \multirow{4}{*}{ Age group } & $15-24$ years & 1 & 0.2 & 1 & n.a. & \multirow{4}{*}{$<0.001$} \\
\hline & $25-34$ years & 2 & 0.2 & $0.8(0.07-9.0)$ & $1^{\mathrm{b}}$ & \\
\hline & $35-49$ years & 4 & 0.4 & $1.8(0.2-15.9)$ & $2.8(0.3-26.9)$ & \\
\hline & $\geq 50$ years & 20 & 6.5 & $32.0(4.2-239.8)$ & $30.9(4.0-239.8)$ & \\
\hline \multirow{6}{*}{ Ethnicity ${ }^{c}$} & White & 25 & 1.1 & 1 & n.a. & \\
\hline & Black African & 0 & 0 & d & n.a. & \\
\hline & Black Caribbean & 0 & 0 & d & n.a. & \\
\hline & Black other & 0 & 0 & d & n.a. & \\
\hline & Asian & 0 & 0 & d & n.a. & \\
\hline & Other & 1 & 0.5 & $0.5(0.06-3.5)$ & n.a. & \\
\hline \multirow{2}{*}{ UK-born } & No & 3 & 0.3 & 1 & n.s. & \multirow{2}{*}{0.239} \\
\hline & Yes & 19 & 1.2 & $4.2(1.2-14 \cdot 3)$ & n.s. & \\
\hline \multirow{2}{*}{ UK-acquired infection } & No & 1 & 0.2 & 1 & n.a. & \multirow{2}{*}{ n.a. } \\
\hline & Yes & 15 & 0.8 & $3.5(0.5-26.3)$ & n.a. & \\
\hline \multirow{2}{*}{ Late diagnosis } & No & 2 & 0.1 & 1 & 1 & \multirow{2}{*}{0.003} \\
\hline & Yes & 15 & 1.8 & $17.1(3.9-74.9)$ & $9.9(2.2-44.1)$ & \\
\hline
\end{tabular}

CI: confidence interval; n.a.: not applicable (not included in multivariable analyses); n.s.: not significant; OR: odds ratio, UK: United Kingdom.

One-year mortality defined as all-cause mortality within twelve months of a HIV diagnosis among newly diagnosed men in a given year.

b Men who have sex with men aged 15-24 years old were excluded from multivariable analyses due to missing CD4 information, and 25-34 year-olds were used as the reference group.

c Ethnicities as reported by clinicians. Black other includes black ethnicities not captured by Caribbean and African ethnicities e.g. black British, black American. Asian includes Indian sub-continent, Chinese and other Asian ethnicities and other includes mixed ethnicity.

d No deaths within a year of diagnosis.

While white, UK-born men aged 25-49 years account for the majority of new HIV diagnoses over the 15 years, the HIV epidemic among MSM has diversified. The largest increases in new diagnoses have been among the youngest and oldest age groups and in 2013 these accounted for $16 \%$ and $11 \%$ of new diagnoses, respectively. The ethnic composition of the epidemic has also expanded with greater numbers of men originating from Asia and central and eastern Europe; in 2013 more than one third of men diagnosed with HIV infection were born abroad. A similar diversity is apparent among men diagnosed late, where a substantial number were of black ethnicity. Importantly, our estimates of country of infection indicate that $66 \%$ of men born abroad probably acquired their HIV infection in the UK. MSM from ethnic minority groups in the UK may face additional challenges including discrimination and isolation. It is therefore vital that prevention programmes provide culturally and linguistically appropriate services for this diverse population of gay and bisexual men and other men who have sex with men.

There are several strengths to our study. The study population is based on comprehensive national surveillance data from multiple sources linked to all-cause deaths reported to the Office of National Statistics. Data quality and completeness are high overall. Nevertheless, there are several limitations. First, some variables were less complete than others. For example, $14 \%$ of men did not have information on country of birth and $15 \%$ were missing CD4 cell count within three months of diagnosis. Reassuringly, no differences were observed between men with and without country of birth or $\mathrm{CD}_{4}$ information (data not shown). Second, linkage between our national HIV surveillance system and the ONS death register does not capture all deaths. However, the remaining deaths are actively followed up to ensure the surveillance system captures the majority of deaths. Third, HIV testing data were only available for STI clinics. However, STI clinics test over half of all individuals for HIV [25] and the majority of new HIV diagnoses among MSM are made in STI clinics [26]; therefore, although MSM can test at other sites, we do not expect substantial HIV testing outside STI clinic settings. Finally, HIV testing data were not available for UK for the entire period and before 2009, testing data for England were not available by age group. We are therefore unable to fully investigate whether 
the increase in new diagnoses among the youngest and oldest men can be accounted for by increases in HIV testing. However, 93\% of all new HIV diagnoses between 1999 and 2013 were reported in England with very little variation in recent years. Trends in new HIV diagnoses in Scotland, Wales and Northern Ireland also follow the same trend as in England (data not shown). For these reasons, we do not believe the exclusion of HIV testing data from the other UK countries would have significantly affected our analyses.

In summary, in the past 15 years of the epidemic in the UK, our data indicate that new HIV diagnoses have continued to rise due to increased testing and high rates of ongoing transmission. Late diagnosis and older age are important predictors of mortality. Despite a decline in late diagnosis, over 900 men present late each year and one-year mortality remains high in this group. Culturally appropriate prevention and testing strategies that are sensitive to a diversifying population require strengthening to reduce HIV transmission and late diagnosis.

\section{Acknowledgements}

We are grateful to all those who continue to collaborate and provide HIV surveillance data. We also thank the HIV and AIDS reporting team for providing new HIV diagnosis data and the STI team for providing HIV testing data.

\section{Conflicts of interest}

None declared

\section{Authors' contributions}

SD led on the data analysis and drafting of the manuscript supported by $S C, A B, G H$ and VD. HM provided HIV testing data. All authors commented on drafts of the manuscript and approved the final version.

\section{References}

1. European Centre for Disease Prevention and Control (ECDC)/ WHO Regional Office for Europe. HIV/AIDS surveillance in Europe 2011. Stockholm: ECDC; 2012. Available from: http:// ecdc.europa.eu/en/publications/Publications/20121130Annual-HIV-Surveillance-Report.pdf

2. Health Protection Agency. 30 years of HIV in the United Kingdom. Health Protection Report; 2011;5(22). Available from: http://webarchive.nationalarchives.gov.uk/20140714084352/ http://www.hpa.org.uk/hpr/archives/2011/news2211.htm

3. Nakagawa F, Lodwick RK, Smith CJ, Smith R, Cambiano V, Lundgren JD, et al. Projected life expectancy of people with HIV according to timing of diagnosis. AIDS. 2012;26(3):33543. http://dx.doi.org/10.1097/QAD.obo13e32834dcec9 PMID:22089374

4. Public Health England. Infectious diseases. [Accessed 6 February 2015]. Available from: https://www.gov.uk/ health-protection/infectious-diseases.

5. Rice BD, Delpech VC, Chadborn TR, Elford J. Loss to followup among adults attending human immunodeficiency virus services in England, Wales, and Northern Ireland. Sex Transm Dis. 2011;38(8):685-90. PMID:21844719

6. Mortimer JY, Salathiel JA. 'Soundex' codes of surnames provide confidentiality and accuracy in a national HIV database. Commun Dis Rep CDR Rev. 1995;5(12):R183-6. PMID:8541940
7. Rice BD, Elford J, Yin Z, Delpech VC. A new method to assign country of HIV infection among heterosexuals born abroad and diagnosed with HIV. AIDS. 2012;26(15):1961-6. http://dx.doi. org/10.1097/QAD.ob013e3283578b80 PMID:22781226

8. Birrell PJ, Gill ON, Delpech VC, Brown AE, Desai S, Chadborn $T R$, et al. HIV incidence in men who have sex with men in England and Wales 2001-10: a nationwide population study. Lancet Infect Dis. 2013;13(4):313-8. http://dx.doi.org/10.1016/ S1473-3099(12)70341-9 PMID:23375420

9. Health Protection Agency. Sexually Transmitted Infections among men who have sex with men in the UK: 2011 Report. London: HPA; 2011. Available from: http:// webarchive.nationalarchives.gov.uk/20140714084352/ http:/www.hpa.org.uk/webw/HPAweb\&HPAwebStandard/ HPAweb_C/1317131680627

10. Jakopanec I, Grjibovski AM, Nilsen $\emptyset$, Blystad H, Aavitsland $P$. Trends in HIV infection surveillance data among men who have sex with men in Norway, 1995-2011. BMC Public Health. 2013;13(1):144. http://dx.doi.org/10.1186/1471-2458-13-144 PMID:23414557

11. Rosinska M, Janiec J, Niedźwiedzka-Stadnik M. Increase of new HIV diagnoses among men who have sex with men in Poland, 2000 to 2011. Euro Surveill. 2013;18(48):20642. http://dx.doi. org/10.2807/1560-7917.ES2013.18.48.20642 PMID:24308981

12. Sullivan PS, Hamouda O, Delpech V, Geduld JE, Prejean J, Semaille C, et al.; Annecy MSM Epidemiology Study Group. Reemergence of the HIV epidemic among men who have sex with men in North America, Western Europe, and Australia, 1996-2005. Ann Epidemiol. 2009;19(6):423-31. http://dx.doi. org/10.1016/j.annepidem.2009.03.004 PMID:19460672

13. Janiec J, Haar K, Spiteri G, Likatavicius G, Van de Laar M, Amato-Gauci AJ. Surveillance of human immunodeficiency virus suggests that younger men who have sex with men are at higher risk of infection, European Union, 2003 to 2012. Euro Surveill. 2013;18(48):20644. http://dx.doi.org/10.2807/15607917.ES2013.18.48.20644 PMID:24308979

14. Mocroft A, Lundgren JD, Sabin ML, Monforte A, Brockmeyer N, Casabona J, et al.; Collaboration of Observational HIV Epidemiological Research Europe (COHERE) study in EuroCoord. Risk factors and outcomes for late presentation for HIVpositive persons in Europe: results from the Collaboration of Observational HIV Epidemiological Research Europe Study (COHERE). PLoS Med. 2013;10(9):e1001510. http://dx.doi. org/10.1371/journal.pmed.1001510 PMID:24137103

15. Zoufaly A, an der Heiden M, Marcus U, Hoffmann C, Stellbrink $\mathrm{H}$, Voss L, et al. ClinSurv Study Group. Late presentation for HIV diagnosis and care in Germany. HIV Med. 2012;13(3):17281. PMID:22093171

16. Shivaji T, Diniz A, Cortes-Martins H. Characteristics of late presentation of HIV infection in MSM and heterosexual adults in Portugal 2011-2013. J Int AIDS Soc. 2014;17(4) Suppl 3;19690. PMID:25397440

17. CASCADE Collaboration. Differences in CD4 cell counts at seroconversion and decline among 5739 HIV-1-infected individuals with well-estimated dates of seroconversion. J Acquir Immune Defic Syndr. 2003;34(1):76-83. http://dx.doi. org/10.1097/00126334-200309010-00012 PMID:14501798

18. Davis DH, Smith R, Brown A, Rice B, Yin Z, Delpech V. Early diagnosis and treatment of HIV infection: magnitude of benefit on short-term mortality is greatest in older adults. Age Ageing. 2013;42(4):520-6. http://dx.doi.org/10.1093/ageing/afto52 PMID:23672932

19. British HIV Association, British Association for Sexual Health and HIV, British Infection Society. National Guidelines for HIV Testing 2008. 2008.Available from: http://www.bhiva.org/ documents/guidelines/testing/glineshivtesto8.pdf

20. National Institute for Health and Clinical Excellence. Increasing the uptake of HIV testing to reduce undiagnosed infection and prevent transmission among men who have sex with men. 2011. Available from: https://www.nice.org.uk/guidance/ph34

21. Department of Health. Improving outcomes and supporting transparency. Part 1A: A public health outcomes framework for England, 2013-2016. 2013. Available from: https://www.gov. uk/government/uploads/system/uploads/attachment_data/ file/263658/2901502_PHOF_Improving_Outcomes_PT1A_v1_1. pdf

22. Hartney T, Kennedy I, Crook P, Nardone A. Expanded HIV testing in high-prevalence areas in England: results of a 2012 audit of sexual health commissioners. HIV Med. 2014;15(4):2514. 10.1111/hiv.12099 PMID:24581335

23. Phillips A, Cambiano V, Nakagawa F, Brown A, Lampe F, Rodger $A$, et al. Increased HIV incidence in men who have sex with men despite high levels of ART-induced viral suppression: analysis of an extensively documented epidemic. PLoS One. 2013;8(2):e55312. 
24. Gazzard BG, Anderson J, Babiker A, Boffito M, Brook G,

Brough G, et al.BHIVA Treatment Guidelines Writing Group.

British HIV Association Guidelines for the treatment of

HIV-1-infected adults with antiretroviral therapy 2008. HIV

Med. 2008;9(8):563-608. http://dx.doi.org/10.1111/j.1468-

1293.2008.00636.x PMID:18826546

25. Public Health England. Annual report from the sentinel surveillance study of blood borne virus testing in England:

data for January to December 2013. Health Protection Report 2014; 8(29). Available from: https://www.gov.uk/government/ uploads/system/uploads/attachment_data/file/345716/ hpr2914_senthep.pdf

26. Tweed E, Hale A, Hurrelle M, Smith R, Delpech V, Ruf M, et al. Monitoring HIV testing in diverse healthcare settings: results from a sentinel surveillance pilot study. Sex Transm Infect. 2010;86(5):360-4. http://dx.doi.org/10.1136/sti.2009.041293 PMID:20427560 